\title{
A honra de poder servir à Sociedade Brasileira de Pneumologia e Tisiologia (SBPT)
}

Após quatro anos, encerro com este número do Jornal de Pneumologia a função de Editora, que exerci por dois mandatos sucessivos e duas gestões diretoras da SBPT.

Estou orgulhosa pelo trabalho realizado e pelas conquistas obtidas, mas sobretudo sintome honrada por ter podido servir à minha sociedade, a SBPT. O servir é para mim a razão mais significativa e profunda da atividade humana e, por isso, finalizo esta tarefa com profunda gratidão.

Sou grata à vida, que em um país pobre como o nosso me permitiu estudar, trabalhar no que gosto, ter escolhas...

Sou grata à equipe da Faculdade de Medicina de Botucatu que abraçou com entusiasmo o projeto de cuidar do Jornal de Pneumologia. Meu jovem colega de disciplina Hugo Hyung Bok Yoo, auxiliar incansável como secretário da revista; Enilze de Souza Nogueira Volpato e Rosemary Cristina da Silva, bibliotecárias do Campus de Botucatu, responsáveis pela assessoria técnica; e Priscilla de Cássia Bovolenta, secretária eficiente e gentil, que de aprendiz está tornando-se mestra.

Sou grata aos membros do Conselho Editorial e aos pareceristas ad hoc, que trabalharam exaustivamente, com seriedade e competência ímpares. Sem o empenho dessas pessoas o Jornal de Pneumologia não teria possibilidade de existir.

Sou grata às duas diretorias da SBPT às quais pertenci (Presidentes: Francisco Elmano Marques de Souza e Luíz Carlos Corrêa da Silva) por terem sempre colocado o Jornal de Pneumologia como prioridade de suas gestões e nos dado todo o suporte necessário.

Sou grata aos autores que submetem seus trabalhos, que respeitam e que acreditam em nossa revista.

Enfim, o somatório do entusiasmo, do trabalho e da competência de todas essas pessoas permitiu a edição de 24 números, que foram lançados rigorosamente nos meses de capa, e 11 suplementos. Neste período, foram analisados 290 manuscritos e publicados 94 artigos originais, 68 relatos de caso, 30 artigos de atualização/revisão, cinco artigos de diagnóstico por imagem, 19 editoriais, 11 artigos de pós-graduação, seis artigos de aprimoramento, 10 artigos de comentários e resumos, quatro resenhas de livro, um artigo de normas da Comissão de Circulação Pulmonar, um artigo de normas do grupo de oxigenoterapia, dois in memoriam e 23 cartas ao Editor. No momento, temos em andamento 39 processos de análise de manuscritos e nossa taxa de rejeição está em torno de 30\%.

A grande vitória foi a indexação do Jornal de Pneumologia pela coleção SciELO Brasil, o que nos colocou entre as 85 principais revistas científicas brasileiras de todas as áreas ${ }^{(1)}$.

Uma das formas de avaliação da qualidade de uma revista científica é a sua indexação em bases de dados. Outra é o seu índice de impacto fornecido pelo Institute for Scientific Information (ISI). Para as revistas brasileiras, a indexação, em especial na Medline, que é a base de dados atual mais importante, é muito difícil e depende muito mais de critérios políticos e econômicos do que qualitativos.

Embora de certa forma o interesse dos leitores, a confiança dos pesquisadores e o encontro de patrocinadores sejam indicadores da qualidade de uma publicação científica, faltava 
uma avaliação mais formal da qualidade das revistas brasileiras. A rede SciELO ${ }^{(2)}$ veio preencher essa lacuna entre nós e se mostra como uma grande promessa para que possa haver uma graduação da qualidade das revistas nacionais, uma vez que as indexadas pela coleção são permanentemente avaliadas por pares. Além disso, a curto prazo, o projeto busca aumentar radicalmente a visibilidade, a acessibilidade e a credibilidade nacional e internacional da publicação científica da América Latina e do Caribe. A longo prazo, busca contribuir para o aumento do impacto da produção científica nacional.

Para obtermos visibilidade internacional é chegado o momento de o Jornal de Pneumologia, através da SciELO, que pode dispor o material da revista em três idiomas, publicar os textos on-line também em inglês - que é o idioma universal da Ciência -, permitindo assim que pesquisadores de todo o mundo tenham acesso às nossas publicações. Para não descaracterizar totalmente a revista, poderíamos utilizar o português na versão impressa e o inglês e o português na versão on-line.

Como última recomendação, reintero aos nossos leitores e/ou autores que é imperativa a melhora dos indicadores de impacto do Jornal de Pneumologia. Para o indicador de uso do periódico, que mede o número de uso do periódico, acesse freqüentemente - e recomende aos seus amigos e alunos que o façam - o Jornal de Pneumologia pelo site da SciELO Brasil ${ }^{(2)}$. Para o indicador de impacto, que mede o número de vezes que o periódico foi citado, temos que citar os trabalhos do Jornal de Pneumologia, valorizando nossa produção científica. Nós não nos citamos! Assim, mantemos o Jornal de Pneumologia e os demais periódicos brasileiros com baixos índices de impacto e não quebramos este círculo vicioso ${ }^{(1,3)}$.

O principal problema de um Editor de revista científica é a falta de formação e/ou de experiência para esta tarefa. Mesmo nos países desenvolvidos, essa é, em geral, uma atividade parcial e transitória, para a qual o indivíduo não tem treinamento específico e seu conhecimento é baseado em habilidades assistenciais, de pesquisa ou até mesmo no trânsito político. São consideradas características de um bom editor: competência, seriedade, imparcialidade e enorme capacidade para suportar pressões ${ }^{(3)}$.

Sou muito grata por estes anos como Editora do Jornal de Pneumologia que me permitiram extenso aprendizado e a busca dessas qualidades. Passo agora o cargo de Editor para Geraldo Lorenzi Filho, um colega da Faculdade de Medicina da Universidade de São Paulo, possuidor das qualidades citadas acima. Como eu e os ex-Editores do Jornal de Pneumologia, ele precisará do apoio da Diretoria da SBPT, do auxílio dos colegas e da confiança dos autores.

Conclamo todos a fazê-lo sem reservas, pois todos temos a missão de, com muita honra, servir à SBPT.

Thais Helena ABRAHÃo THOMAZ QUeluz Editora

E-mail:queluz@fmb.unesp.br

\section{REFERÊNCIAS}

1. Queluz TT. Admissão do Jornal de Pneumologia na SciELO Brasil: uma vitória com novos desafios. J Pneumol 2002;28:IX-X.

2. SciELO. www:scielo.org.

3. Kassirer JP. Editorial: Why be a medical editor? JAMA 2001;285:2253. 